\title{
ANTROPOLOGIA, REFLEXÃO E AÇÃO: entrevista com Luciana Chianca
}

\section{ANTHROPOLOGY, REFLECTION AND ACTION: interview with Luciana Chianca}

Luciana Chianca*

Maysa Carvalho de Souza**

\begin{abstract}
Luciana de Oliveira Chianca é professora associada do Departamento de Ciências Sociais da UFPB, e atua no Programa de Pós-Graduação em Antropologia na mesma instituição. Sua trajetória acadêmica transita pelas ciências sociais, com ênfase na antropologia. Motivada pela busca e disseminação dos conhecimentos, dialoga com diversas áreas. Como pesquisadora notabiliza-se pelos estudos sobre a cultura popular, o patrimônio cultural, imaterial, as dinâmicas urbanas e a globalização da cultura. Leciona desde 1995 e notabiliza-se por suas metodologias de ensino premiadas. Definese como uma antropóloga de múltiplas fontes. Defende e atua nas atividades e projetos de pesquisa, ensino e extensão universitários, com destaque à coordenação do projeto Pamin, projeto de pesquisa e extensão desde 2012. É paraibana, autora de diversos livros e artigos acadêmicos de relevância nacional e internacional. A entrevista foi realizada por correspondência de email entre os meses de abril e maio de 2020, haja vista a necessidade de isolamento/distanciamento social imposto no Brasil a partir de março desse ano, por causa da pandemia provocada pelo novo coronavírus (SARS-Cov-2).
\end{abstract}

Maysa Carvalho - Professora Luciana, eu gostaria de iniciar pedindo que nos contasse um pouco sobre sua origem e sua trajetória.

Luciana Chianca - Vivo em João Pessoa desde minha infância. Depois morei em Campina Grande, na França e em Natal, com migrações sempre motivadas por estudo ou trabalho. Estudei na UFPB tanto na graduação quanto no Mestrado. Fiz meu Doutorado na França, e sou professora de universidades públicas (UFPB e UFRN) desde 1995.

Maysa Carvalho - Por que ciências sociais? Quando surgiu o interesse? Nos conte sobre a sua formação.

\footnotetext{
* Professora associada do Departamento de Ciências Sociais da UFPB/ Brasil. Doutora em Antropologia pela Université Bourdeaux 2/França. E-mail: lucianachiancaufpb@yahoo.com.br.

** Mestranda do Programa de Pós-Graduação em Sociologia/UFPB/Brasil. E-mail: maysa_souza12@hot mail.com.
} 
Luciana Chianca - Meu interesse pelas ciências sociais surgiu no ensino médio, porque essa formação me aproximava de uma abordagem da sociedade (e da cultura) que envolvia várias disciplinas sociais e humanas, como a psicologia, história, geografia, urbanismo, arquitetura, demografia, letras, filosofia, artes, e as ciências da natureza, da vida, da saúde, as tecnologias e a comunicação. Fiz meu curso de ciências sociais na UFPB (área de concentração em ciência política), em Campina Grande nos anos 1980, antes de ela se transformar em UFCG. No TCC, fui orientada pelo querido professor Rômulo de Araújo Lima, um sociólogo. Logo em seguida, fiz meu Mestrado em João Pessoa no Programa de Ciências Sociais (antes de ser renomeado PPGS), sob orientação da professora Simone Carneiro Maldonado, uma antropóloga fenomenal. Meu doutorado foi em Antropologia, na Université Bordeaux 2, França, muitos anos depois, sob direção do grande professor Christian Mériot. Devo muito a esses três mestres; foi para eles que dediquei meu primeiro livro.

Maysa Carvalho - Além das ciências sociais, interessa-se por outras áreas? Quais?

Luciana Chianca - Me interesso por tudo que existe, e pelo que talvez não consigamos perceber, sentir e compreender no momento. Por isso todas as artes e domínios do conhecimento, sejam elas formais ou não, me interpelam e provocam minha curiosidade. Motivada para conhecer e disseminar esse conhecimento (que não faz sentido “estacionar" em mim mesma), me interesso muito pelos processos de cognição e ensinoaprendizado, metodologias de ensino, currículos e didáticas - temas tradicionalmente localizados na pedagogia e nas ciências da educação, de modo mais amplo.

Maysa Carvalho - Quando começou a lecionar?

Luciana Chianca - Iniciei minha carreira de professora de magistério superior em 1995, por meio de concurso público, na Universidade Federal do Rio Grande do Norte, para a disciplina de Teoria Antropológica. Desde então, atuo no ensino público e gratuito nacional, o que muito me orgulha, porque nestas instituições encontramos um ensino de excelência, prezando sempre por sua qualidade e democratização, buscando constantemente amplificar seu acesso e permanência aos setores socioeconomicamente menos favorecidos de nossa sociedade. Antes dessa experiência, fui professora de português (conversação) em aulas particulares, o que é muito diferente de uma sala de 
aula convencional. Considero que aprendi a ensinar por meio de meus diferentes professores, alunos e colegas de trabalho.

Maysa Carvalho - Academicamente, quais são suas influências teóricas e metodológicas?

Luciana Chianca - Há tantos autores que me influenciam quantas são as questões que me disponho a compreender, e segundo suas especificidades, remeto-me aos diversos autores e teorias a fim de realizar a síntese teórico-metodológica mais apropriada. Tive uma formação tradicional em ciências sociais muito pautada nos clássicos de nossa disciplina, conhecidos na minha época como "os três porquinhos": Émile Durkheim, Karl Marx e Max Weber. Penso que a sociologia e a antropologia que lhes seguiram são herdeiras desse trio; tradição que também está presente em tudo que penso e publiquei, desde meu TCC de graduação. O pensamento deles foi matizado e sofisticado pelos autores posteriores, e mesmo nas mais revolucionárias das correntes contemporâneas, identificamos suas influências. Sou uma antropóloga de múltiplas fontes: G. Simmel, M. Foucault, F. Barth, Michel de Certeau, M. Halbwachs, entre tantos. Mas destaco Pierre Bourdieu, que foi muito feliz em sua síntese intelectual e teórica da sociedade capitalista contemporânea em seus processos simbólicos e culturais.

Maysa Carvalho - Pensando em termos de socialização e representatividade, quais são as mulheres que a senhora elencaria como principais influências em sua vida?

Luciana Chianca - Não vou citar grandes personagens, fico com minha pequena história: começo por minhas avós, Corina e Eutália. Elas fazem a conexão entre o tempo que passou e o presente, que compartilho com minha mãe e minhas filhas. Essas três me ajudam a entender o mundo de hoje. Como não tive irmãs, considero minhas professoras e mestras como amigas, e muitas delas assumiram esse papel de fato. Algumas ex-alunas também se tornaram amigas, o que é uma grande sorte! Tenho muitas amigas, algumas de infância, outras da adolescência e outras da fase adulta da vida: todas são minhas irmãs. Todas elas são referências na minha vida, lembrando que ontem, hoje e amanhã, o lugar de mulher é onde ela quiser. O que não é fácil, mas deve ser nossa ambição.

Maysa Carvalho - Professora, na edição do Exame Nacional do Ensino Médio (ENEM) do ano de 2019 foi formulada uma questão a partir de um artigo de sua autoria intitulado 
"Devoção e diversão: expressões contemporâneas de festas e santos católicos", publicado em 2007. Quais suas impressões acerca dessa experiência?

Luciana Chianca - Muita gente viu e soube antes de mim, pensei que fosse fake news, e até duvidei. Foi curioso e um pouco desconcertante, porque foi um reconhecimento inesperado e anônimo. Como não sou uma star acadêmica, todas as citações me encorajam, mas nesse caso em que aquele trecho atingiu milhões de leitores e o tema abordado poderá interessar algumas dezenas ou centenas de pessoas, isso me alegrou muito. Mas nunca saberei quem utilizou essa citação para a questão da prova do ENEM e nem quando ela foi feita, porque soube depois que é um processo complexo que envolve um banco de questões elaborado por vários professores ao longo dos anos. E pensar que a festa junina foi um tema considerado pouco relevante por muitos cientistas sociais quando comecei a estudá-lo no final dos anos 1980... Mas o sentido da publicação é esse mesmo: tornar acessível aos outros as nossas pesquisas e a nossa reflexão, mesmo que sejam em geral só algumas dezenas de leitores. Não é a quantidade que conta, mas a qualidade e o interesse do leitor.

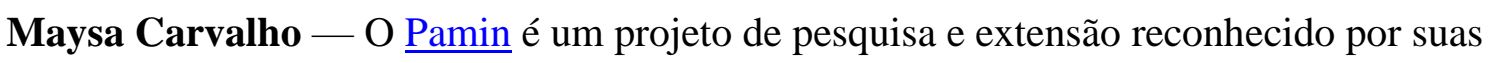
ações relacionadas ao estudo do patrimônio cultural e imaterial. Como ele surgiu?

Luciana Chianca - Ele surgiu de uma constatação bem simples: a criatividade artística e cultural de nossa cidade é invisível, pois não frequenta os eixos centrais (e oficiais) de sua circulação e consumo. Grosso modo, quem define esses eixos é o mercado (mídias diversas, produtoras e difusores), e o Estado (prefeituras e governos estaduais e federal). Isso se repete em vários lugares do mundo. No contexto do surgimento do Pamin, o Brasil estava numa fase muito auspiciosa, com um governo eleito pela vontade popular e que demonstrava também grande interesse por essa produção artística e cultural não dominante, não comercial, não consumista. Gilberto Gil era o ministro da Cultura, e toda a política cultural do governo federal incentivava a emergência dessas expressões até então invisíveis com uma grande capacidade de mobilização, como um reconhecimento da sua poderosa vitalidade. De outra parte, estávamos em pleno boom digital, e as opiniões se dividiam em duas, e aqui faço referência a Umberto Eco: havia os apocalípticos e os integrados. Simplificando o debate, diria que os primeiros eram céticos: a cultura digital só reforçaria o poder dos poderosos. Os integrados acreditavam como eu, 
que seria possível utilizar a potência do digital para proporcionar uma maior democratização da cultura com seus matizes populares ancorados na expressão tradicional, vinculados às memórias locais e expressando as suas condições de emergência. Procurei o Lavid (Laboratório de Vídeo Digital) do Centro de Informática da UFPB, onde esta demanda teve uma ótima acolhida. A partir de então, trabalhamos para constituir um site (e depois um aplicativo de celular) que permitisse o registro colaborativo destas expressões populares, o que fizemos de 2012 a 2017.

Maysa Carvalho - A atuação do Pamin no município de Alhandra - PB foi marcada pela proposta de diálogo entre estudantes de uma escola e os patrimônios culturais locais, resultando no destaque ao culto da "jurema sagrada". Como ocorreu esse processo?

Luciana Chianca - Foi um grande aprendizado. Realizamos ali um inventário colaborativo para o Pamin com muitas trocas de saberes e experiências. Uma delas consistia em pedir aos jovens da Escola Estadual Renato Ribeiro Coutinho que nos apresentassem sua cidade. Sabíamos que Alhandra é uma referência da jurema, com vasta referência em obras e autores da antropologia, mas o tema permanecia encoberto pelos alunos que nos revelavam a história colonial da cidade com muita facilidade, mas omitiam esse aspecto tão importante, apesar de o principal centro de culto da jurema estar defronte à escola. Esta descoberta feita com os alunos e com os professores da escola que aderiram ao projeto chama atenção para os aspectos do poder na seleção da memória social local.

Maysa Carvalho - Quais são as perspectivas futuras para o Pamin?

Luciana Chianca - Pouco a pouco, o Pamin vai se consolidando como uma linha de pesquisa e extensão envolvendo a extensão e também projetos e programas de pesquisa com estudantes de graduação e pós-graduação, agrupadas sob os temas do patrimônio, da memória e da identidade. Também realizamos publicações em torno do tema do patrimônio, e promovemos eventos formativos, como o Veredas do Patrimônio, que terá sua quinta versão em 2021. Apoiamos e participamos de eventos, pesquisas e mantemos um diálogo constantes com outros setores da UFPB, e com outras universidades e instituições, como o Iphan e o Iphaep, ongs e outros grupos de pesquisa da UFPB, como o ObservaCult e o Redmus. 
Maysa Carvalho - O Pamin foi contemplado com o prêmio Elo Cidadão em 2016, com destaque para o uso das redes sociais como meio de comunicação no projeto. Quais foram as redes sociais utilizadas pelo projeto e quais eram as metodologias?

Luciana Chianca - Entre 2015 e 2016, o Pamin atuou diretamente com o Centro Cultural Piollin e seus educandos, realizando com eles um inventário participativo sobre o patrimônio imaterial do bairro do Roger. Este trabalho está na base de artigos e videodocumentários realizados pelo Pamin. Entre nossos bolsistas havia estudantes de várias áreas, além das ciências sociais e das ciências da computação. Contávamos também com estudantes de história, ciências da informação e comunicação social, e nos dividíamos em equipes, cada uma com suas próprias atividades. A equipe de comunicação social colaborava em divulgar as atividades do Pamin na página de Facebook do Pamin e do Piollin. O relato dessa rica experiência rendeu esse prêmio a nossas duas bolsistas: Laísa Gomes Mendes e Luiza Maria Rocha de Araújo, e a mim como orientadora. Ficamos muito felizes e gratas pelo reconhecimento da UFPB, por meio de sua ProReitoria de Extensão.

Maysa Carvalho - Quais as suas reflexões acerca da difusão das mídias digitais e das redes sociais?

Luciana Chianca - As "redes sociais" são processos sociológicos estudados há muitas décadas e ocorrem de modo presencial, à distância, envolvendo grupos maiores ou menores, segundo o caso. Mas acho que sua pergunta é sobre as chamadas "redes sociais" digitais que funcionam baseadas nos princípios das redes sociais tradicionais, mas têm uma amplitude potencializada pela velocidade, e nesse caso também conta muito a facilidade do acesso à informação. Acrescentando rapidez e agilidade ao fluxo informacional, as mídias digitais favoreceram a velocidade da notícia. Elas são mídias, ou seja, meios de informação que circulam por via digital, o que significa que a informação agora prescinde de suporte material (o papel, por exemplo). Mas já conhecemos os riscos e perigos dessa velocidade informacional, porque ela está na base da superficialidade da informação, que leva às fake news: estamos cada vez mais mal informados ou desinformados com tanta informação falsa, errada ou inútil. No nosso trabalho, elas possibilitam uma maior divulgação e acesso aos projetos, assim como viabilizam um registro das atividades realizadas em tempo real, o que o Prêmio Elo 
Cidadão destacou com o Pamin no Piollin. Nesse sentido, as redes sociais digitais são uma excelente ferramenta para grupos, pessoas e projetos que não têm acesso a uma publicidade mais ampla. Mas a força das redes sociais não digitais continua presente, e elas são fundamentais para sustentar os fazeres e saberes que antecedem e sucedem às notícias ou registros em redes ou mídias digitais.

Maysa Carvalho - Como isso interfere no cotidiano acadêmico?

Luciana Chianca - Há um campo no qual a digitalização - e o acesso facilitado à informação pela internet - é excelente: na divulgação de revistas, obras científicas, jornais e periódicos, no acesso à produção e criação artísticas, antes, de circulação muito restrita. Também encontramos mais facilmente as pessoas, e o acesso a elas é facilitado pelo e-mail ou pelas redes sociais para quem as utiliza. No nosso cotidiano também precisamos facilitar a interação com o público, seja ele externo ou interno à universidade: alunos, comunidades, grupos, artistas, associações e coletivos nos procuram mais facilmente, de modo que suas demandas qualificadas, seja por autonomia, crescimento ou maior estabilidade estimulam nossa colaboração, reciprocamente tão importante. Sabemos que é próprio da comunicação viabilizar essa relação, seja pela via digital ou física - lembrando que as redes presenciais e diretas asseguram a formação de vínculos mais profundos, com malhas muito duradouras e resistentes.

Maysa Carvalho - Como o uso das redes sociais e das mídias digitais podem contribuir para o desenvolvimento de programas ou projetos financiados pela universidade?

Luciana Chianca - Creio que seu papel é vital, tanto no aspecto da comunicação já citado, como da transparência, no sentido de tornar públicas as nossas ações, projetos e programas de ensino, pesquisa, extensão e inovação. Porque a despeito da sua importância no cenário local, por exemplo, poucos paraibanos têm a visão da Universidade Federal como produtora de conhecimento. Muitos consideram apenas seu caráter formativo de alunos, por meio de aulas, cursos e outras formações. Para estes, somos "apenas" professores. Já seria muito, mas também somos pesquisadores, extensionistas, gestores, criadores e inventores.

Maysa Carvalho - Professora, em um artigo de sua autoria intitulado "Patrimônio, memória e tecnologias digitais” (CHIANCA, 2013), há uma discussão acerca da 
contemporânea cultura digital e como as produções populares são por vezes escanteadas dos eixos tradicionais de informação. Poderia comentar mais acerca disso?

Luciana Chianca - Esse artigo trata da formação do Pamin e sua relação com a democratização da produção artística e cultural, dos patrimônios materiais e imateriais dos setores menos favorecidos social e economicamente. Tome o exemplo de uma tribo de índios, escola de samba ou quadrilha junina do Roger. Elas estão entre as mais antigas da cidade, conseguiram resistir a todas as dificuldades e se reinventaram diante das transformações históricas e culturais que sacudiram o século XX. Deram provas incontestáveis de sua vitalidade e da potência que as vincula com a sua comunidade, mas quase não se ouve falar delas! Não é incrível? Um pouco no Carnaval e um pouco no São João. Acabou. Mesmo os meios de comunicação digital reproduzem a lógica das televisões, rádios e jornais em que "cultura” é teatro, cinema, exposições e shows de artistas famosos. Em geral, é pago ou distante; quem mora perto da Orla ou do Centro Histórico? É difícil e dispendioso ir e vir para esses lugares - e algumas vezes até valeria a pena ver. É um sistema muito desigual e prioriza a elite. Enquanto isso, os bairros fervilham em festas, celebrações, jogos e rituais; a cultura em outras formas. Mas os sites de notícias da cidade (mídias digitais) só se dedicam ao Roger em suas páginas policiais. Então há um circuito de informação que oculta e inviabiliza essas cores, sons, cheiros e movimentos.

Maysa Carvalho - A senhora tem muitas publicações, e a maior parte delas direcionamse aos temas de cultura, festas, patrimônio, e como mencionado anteriormente, servem de referência para muitos estudos nacionais e internacionais. Recentemente, de uma só vez, a senhora nos presenteou com quatro livros. Um deles é "Ciganos: olhares e perspectivas”, que escreveu em coautoria com Patrícia Goldfarb e Marcos Toyansk (GOLDFARB; TOYANSKY; CHIANCA, 2019). Poderia nos falar sobre a construção dessa publicação?

Luciana Chianca - Sou uma fã do trabalho da professora Patrícia Goldfarb desde que li o livro que ela publicou pela Editora UFPB, em 2013: "Memória e etnicidade entre os Ciganos Calon em Souza/PB”. Como um dos resultados de seu doutoramento na UFRGS, esse livro revela como os Calon de Souza são resultado de sua própria história, e como a sua permanência naquela cidade é fundamentada por um rico diálogo da comunidade com 
seu entorno, destacando a memória de diferentes "tempos" para constituir uma tradição e projetar um futuro que responda a suas demandas políticas, étnicas e territoriais. Em minha tese de doutorado, trabalhei com os conceitos de identidade e memória que também fundamentam a análise de Patrícia, mas tematizei outros migrantes: os trabalhadores citadinos de origem rural que povoam o imaginário da cidade, tanto no cotidiano quanto em tempos de festa junina. Quando ela me convidou para esse diálogo aceitei de imediato, porque nossa interlocução teórica no campo da antropologia tem se intensificado a cada nova experiência que empreendemos juntas. O livro "Ciganos: olhares e perspectivas", organizado também por Marcos Toyansk (USP), nos presenteia com a produção de uma vasta rede de colaboradores, interlocutores e referências nacionais e internacionais sobre a etnicidade e a identidade cigana. Fazer parte desse projeto foi uma honra para mim.

Maysa Carvalho - Outro livro, dessa leva recente, é o "Vozes do Roger" (CHIANCA; OLIVEIRA; SOUZA, 2019). Pensando a cultura e as memórias enquanto narrativas que ecoam no espaço e no tempo, como a senhora descreveria as vozes que ecoam nesse livro? Luciana Chianca - É uma polifonia impressionante. Esse livro, que apresenta o cotidiano artístico, cultural, religioso e a sociabilidade dos moradores do Roger revela a intensa dinâmica dessas pessoas, mobilizando cotidianamente a todos, seja em escolas de samba, quadrilhas juninas, ala ursas, corridas de argolinha, rodas de capoeira, cultos e práticas religiosas de variadas matrizes históricas. No cotidiano são majoritariamente trabalhadores e estudantes, que em momentos de festa e celebração se transfiguram em artistas, criadores e mobilizadores sociais de grande potência criativa. O problema é a inviabilização que eles sofrem no dia a dia, por serem moradores de um bairro associado ao antigo Lixão municipal e à penitenciária Flósculo da Nóbrega, que é do Estado da Paraíba, e não do Roger. São estigmatizados por serem trabalhadores urbanos, pobres, ou por serem negros, ou os dois, ou os três. Mas representam a sua própria resistência, resiliência e capacidade de reinvenção. Por isso o Pamin idealizou e organizou esse livro, deixando ecoar essas vozes em entrevistas abertas autorizadas e revisadas por todos os que ali estão apresentados. Desejo que essa modesta contribuição amplifique a força daquela memória, ressoando cada vez mais alto a força dos seus dizeres e dos seus cantos, acompanhados ou não de tambores, sanfonas, atabaques, berimbaus ou tamborins. 
Maysa Carvalho - A temática de cultura é um elemento presente tanto na sua trajetória de formação quanto nas publicações e produções. Como e quando surgiu seu interesse por essa área que transita entre os saberes das ciências sociais?

Luciana Chianca - Fui criada por pais muito sensíveis à cultura e às artes, em suas diferentes formas e expressões. Na minha infância, assisti a exposições de artes plásticas, concertos de orquestras, filmes de arte, peças de teatro e corais. Ambos nordestinos, meus pais me levavam para visitar artesãos, rendeiras, músicos, feiras e mercados, parques e praças, cidades históricas importantes e vilarejos desconhecidos, com pescadores artesanais. Cresci nesse ambiente de respeito pelos saberes tradicionais e pela cultura erudita ao mesmo tempo. Como eles também eram professores, convivi desde criança com profissionais e pesquisadores de várias origens, do Brasil e de outras nacionalidades. Quando criança, moramos fora do Brasil, o que nunca foi apresentado nem sentido em casa como uma distinção, vantagem ou privilégio, porque fomos para estudar e vivemos como estudantes, e depois voltamos todos para o Brasil. Tudo isso me ensinou a diversidade, o respeito e a admiração das diferenças, da beleza e da riqueza que é inerente a todas as culturas. Acho que meu interesse de compreender a cultura veio desse melting pot.

Maysa Carvalho - A festa junina do São João foi o elemento central que perpassou suas produções principais para a obtenção de títulos acadêmicos. Como surgiu seu interesse por essa festa?

Luciana Chianca - Fiz minha graduação em ciências sociais em Campina Grande, na antiga UFPB-campus II, no bairro de Bodocongó. Apesar de conhecer a festa junina desde criança, pude testemunhar o surgimento e a construção (por assim dizer) do Maior São João do Mundo, que é o nome oficial da festa urbana centralizada, midiática, turística e espetacular que se consolidou naquela cidade desde metade dos anos 1980 até a presente data. Passou por algumas modificações, mas tem como marco histórico e foco festivo o Parque do Povo. Pois bem; eu estava ali quando tudo começou. Precisava de um tema para TCC em ciência política, e esse investimento da Prefeitura na festa tradicional me pareceu um bom assunto, ainda mais que no final do curso eu comecei minha guinada em direção à antropologia. Hoje em dia percebo que foi uma ótima ideia, embora tenha sido recebida com indiferença por muitos professores de ciências sociais na época. Ao 
contrário do meu orientador, o professor Rômulo de A. Lima, que incentivou e encorajou minha ousadia intelectual, razão pela qual lhe serei eternamente reconhecida. Desde então a festa junina me acompanhou no mestrado, doutorado, em pesquisas, videodocumentários, artigos, entrevistas, e tudo o mais, e recentemente, no ENEM 2019. Ao longo desses 30 e poucos anos fui aprendendo cada vez mais sobre a festa e alguns temas que lhe são correlatos como o forró, a quadrilha, a migração, o catolicismo oficial e o popular, o folclore, a alimentação. A festa junina é um fato social total.

Maysa Carvalho - Após a extinção do Ministério da Cultura e com a transição do mesmo para uma secretaria vinculada ao Ministério da Cidadania, a questão da cultura no Brasil perpassa uma fase de polêmicas. Quais seus pensamentos acerca disso?

Luciana Chianca - Repudio, enquanto lamento profundamente a recente extinção do Ministério da Cultura do Brasil, porque ele garantia a execução de políticas e programas públicos de grande significado e importância para nosso país. O seu desaparecimento testemunha a falta de sensibilidade dos que não percebem a importância de respeitar e valorizar a cultura brasileira como valor ético, moral, identitário. Num plano mais local e pragmático, a cultura articula muitos setores produtivos, porque além de ser um conceito, a cultura é vivida pelas pessoas através da culinária, das artes, festas, celebrações, comunicação, arquitetura, agricultura, pesca, comércio etc. Reconhecer a importância da indústria da cultura seria reconhecer o potencial da criação e da invenção, mas isso exige duas coisas que estão ameaçadas no nosso país: liberdade de pensamento e de expressão. Diferentemente do que propõe o modelo liberal, a arte e a cultura (e a educação, a saúde) não podem estar subordinados à lógica do capital, razão pela qual cabe à sociedade e ao Estado garantir as condições de sua produção e fomento com estímulos financeiros distribuídos de maneira transparente e equânime, de modo a potencializar o conhecimento, a vida, a criatividade e a inventividade humana.

Maysa Carvalho - Um assunto muito discutido atualmente é a turistificação e espetacularização da cultura popular. Quais as suas concepções acerca da relação entre a cultura popular e o turismo?

Luciana Chianca - Essa é uma questão que convém considerar com muita delicadeza, pois ela ocorre à revelia de nossa opinião; são processos sociológicos que não cabe a nós julgar, mas compreender. Pelo que temos visto, esse processo é quase universal e 
contínuo, ou seja, com a difusão de conhecimentos e informações, rapidamente podemos nos inteirar de uma cultura ainda não espetacular ou turística. E o desejo de conhecer é também uma universal humana, não necessariamente negativa. Nem todo turismo é predador, embora essa seja a mais forte tendência nos países pobres, como é o caso do Brasil, onde em geral ele ocorre de modo desorganizado e desigual, provocando danos irreversíveis aos grupos nativos. Então é preciso considerar as situações, porque, às vezes, esse contato é desejado e buscado pela própria comunidade que, por exemplo, quer se desenvolver de modo sustentável. Numa sociedade que busca o lucro e a mais valia, o que podemos esperar da relação turística ou da cultura enquanto espetáculo? Se os polos da relação são muito desiguais, fica reforçada uma exploração que empobrece a cultura popular. Mas em alguns casos, os nativos se fortalecem, por meio de estratégias de mercado e produção de renda que abrem perspectivas econômicas e culturais antes inimagináveis. Há um antropólogo argentino chamado Nestor Garcia Canclini que discute muito essas questões, e sua análise revela a complexidade de situações e temas que encontramos caso a caso. Turismo e espetáculo não são necessariamente negativos para a cultura popular.

Maysa Carvalho - No curso de Ciências Sociais da UFPB, percebe- se que há pouco investimento em atividades de extensão, havendo um maior interesse direcionado ao ensino e a pesquisa. Contudo, desde o início de sua carreira profissional, a senhora vem se dedicando à extensão universitária. No ENEX (Encontro Nacional de Extensão) ocorrido em 2016, ao mencionar o projeto Pamin e a sua atuação enquanto coordenadora, a banca avaliadora fez grandes elogios mencionando a professora Doutora Luciana Chianca como uma "guerreira da extensão". Quais seus pensamentos acerca dessas considerações? E qual a importância da extensão universitária para a formação dos discentes?

Luciana Chianca - O Pamin deve ser creditado a um importante Programa Federal dirigido à extensão universitária nas instituições de ensino brasileiras, o PROEXT. Vinculado ao Ministério da Educação, ele estimulava e reforçava nossas atividades de extensão, que na UFPB eram desenvolvidas com o apoio da PRAC, antigo nome da PróReitoria de Extensão. Infelizmente esse programa (o PROEXT) foi suspenso em 2017. Para mim, todos os professores que trabalham com a extensão universitária são, de certa 
forma, guerreiros, porque ela é tratada como a "prima pobre" da universidade, e seus executores também, por analogia. As universidades reservam seus orçamentos e espaços privilegiados para a pesquisa, que é elegante, "classuda", distinta. Não vou dizer como a extensão é considerada, basta recuperar os antônimos desses adjetivos. Independentemente dessa imagem estigmatizante, me envolvi na extensão desde meu primeiro passo na universidade como professora, ainda nos anos 1990. Foi num projeto de educação de jovens e adultos, chamado Alfabetização Solidária, que me levou aos confins do Rio Grande do Norte. Depois atuei no Conexão de Saberes, outro programa federal de extensão que contribuía para a integração de alunos de origem popular na universidade, no começo dos anos 2000. Dessa vez, meu campo era a própria UFRN e seus alunos. Mais recentemente, nos anos 2010, já na UFPB, atuei no PROEXT com o Pamin, buscando a população socioeconomicamente desfavorecida em João Pessoa e Alhandra, PB. Sem falar nos projetos de extensão que "inventei" e coordenei na UFRN e na UFPB. Em todas essas experiências aprendi que sigo aprendendo, e que não há pesquisa nem aprendizado pleno (ensino sim, talvez) sem o diálogo comunidadeuniversidade. Manter essa articulação com ela é nossa função social. Por isso, a extensão é fundamental para os alunos e deve acontecer sempre que possível, pois lhes propicia uma dimensão extraordinária de experiências e vivências, permitindo-lhes uma crítica construtiva sobre o conhecimento científico - que não é melhor nem pior que o prático e popular. A antropologia exercita essa relação permanentemente, mas nem todos os antropólogos são extensionistas. Poucos sabem o que é a extensão universitária e a dimensão que ela abarca, o que é uma pena. Mas creio que essa visão vai se modificar aos poucos.

Maysa Carvalho - Ainda em relação às atividades de extensão promovidas pelo Pamin, poderia nos falar sobre o "Veredas do Patrimônio"?

Luciana Chianca - O Veredas do Patrimônio surgiu no seio do Pamin como uma atividade formativa dos nossos bolsistas e aberto à comunidade, organizando atividades diversas que envolvessem nossos alunos no tema do patrimônio cultural. Elas acontecem desde 2014, e suas quatro diferentes versões atingiram muitas "gerações" de bolsistas do Pamin. Como é um evento aberto a outros parceiros e públicos, ele intenta ampliar o olhar da sociedade sobre o patrimônio, ampliando nossa rede de diálogos, debates e parcerias. 
Para conduzir a discussão sobre o patrimônio, que é muito vasta, focamos em temas a cada edição. No primeiro ano, o tema foi mais geral, em torno de "Teorias, experiências e políticas contemporâneas". Em 2016, debatemos “O desafio dos inventários”, enquanto seguimos em 2017, "Nas Tramas da Memória”. Na quarta e última versão, o tema foi "Margens, imagens e fluxos". Procuramos sempre realizar uma programação diversificada com exposições fotográficas, mostra de vídeos, palestras, mesas redondas e cines-debate; convidamos professores, pesquisadores e profissionais atuantes no campo do patrimônio para revelar faces pouco conhecidas da nossa realidade patrimonial. Esses eventos também resultaram em duas publicações lançadas em 2019 pela Editora UFPB: "Nas trilhas da memória", que organizei com a professora Geovânia Toscano (CHIANCA; TOSCANO, 2019), e "Veredas do patrimônio", com a professora Patrícia Pinheiro (CHIANCA; PINHEIRO, 2019).

Maysa Carvalho - A senhora já teve muitos alunos (as) e orientandos(as). Como avalia o resultado de seu trabalho na formação deles e delas? Quantos seguiram em frente estudando a temática da cultura popular?

Luciana Chianca - Essa questão é muito delicada: como avaliar a repercussão de meu trabalho sobre centenas de alunos, depois de mais de 25 anos de atuação em ensino na UFRN e UFPB? São muitos alunos, de cursos diferentes, com origens, horizontes e perspectivas diversas. Os orientandos são os alunos com os quais mantenho uma relação que se consolida melhor, porque se prolonga na duração e qualitativamente, permitindo uma maior troca de informações, experiências e apreciações. Então, em vez da repercussão do meu trabalho sobre eles, prefiro falar sobre o impacto que eles tiveram sobre mim. E é impressionante, porque são relações muito peculiares a cada vez. Quando eles me procuram com seus temas e ideias de pesquisa, procuro encontrar um campo comum de interesses onde nós estejamos à vontade. Quando isso não acontece, é um desastre, porque não nos envolvemos com a mesma intensidade e o resultado pode sair, mas fica distante de nós. Então acho que essa interação é fundamental para que a pesquisa deles repercuta sobre eles e sobre mim, e para que eu siga aprendendo, por meio deles. Muitos seguiram estudando a cultura popular, mas não sei a proporção nem a quantidade exata, até porque oriento alunos que pesquisam diversos temas. Inclusive eu aprecio essas variações, e não busco "converter" meus alunos a meus interesses, temas e linhas de 
pesquisa: procuro formá-los para que sejam cientistas sociais plenos, críticos e autônomos, e para que eles atuem onde e com quem puderem. Os trabalhos precisam ser propositivos, viáveis e relevantes, é o que busco construir com eles. Mas não procuro construir um séquito de alunos e orientandos. Pelo contrário, gosto muito quando encontro com eles por aí, felizes e já distantes de mim — de preferência quando estão realizados profissional e pessoalmente.

Maysa Carvalho - A Associação Brasileira de Antropologia (ABA) com o apoio da Fundação Ford realizou um concurso para projetos inovadores no ensino de antropologia. Dentre os premiados, havia o seu projeto voltado para alunos da graduação em ciências sociais da UFRN. Quais seriam os critérios para um ensino inovador na área da antropologia?

Luciana Chianca - Como disse há pouco, não trabalho para "converter" alunos em antropólogos. Não sou proselitista. Não acho que a antropologia seja "melhor" que as outras disciplinas. O projeto premiado em 2006, chamado Interfaces Humanísticas da Antropologia, destacava essa forma de ver o ensino da antropologia, que não deve se distanciar do conjunto de disciplinas com as quais ela sempre dialoga. A divisão de disciplinas é importante para que todas tenham crescimento e autonomia, mas não podemos esquecer que a dinâmica social com seus processos (a "vida real"), não está confinada num campo disciplinar específico. Por isso, precisamos dialogar com a sociologia e a política, mas também com a história, a geografia, a filosofia, o urbanismo, a educação, e todas as demais disciplinas, conforme demande o campo em que a antropologia seja instada a colaborar. Foi assim que surgiram a etnomatemática, a etnobotânica, a etnozoologia, a etnomusicologia, a etnoastronomia, e por aí vai.

Maysa Carvalho - Qual a sua percepção acerca do ensino das ciências sociais nas universidades brasileiras atualmente?

Luciana Chianca - Creio que estamos diante de um momento de muitos desafios. O maior deles é resistir àqueles que não compreendem o lugar da sociologia, da antropologia, da ciência política e da filosofia nas escolas e universidades. Precisamos estar cientes da nossa importância e papel histórico, porque somos disciplinas críticas, por definição. Então cabe a nós refletir e questionar os ataques que vimos recebendo, e o ensino das ciências sociais é o espaço certo para isso, porque fornece aos alunos os 
instrumentos teóricos, metodológicos e reflexivos fundamentais à nossa identidade. Mesmo se ele vem sendo ameaçado, o ensino das ciências sociais demonstra sua vitalidade, resistência e capacidade de recuperação, porque no Brasil somos profissionais com grande inserção em associações, sindicatos, e grupos de pesquisa nacionais e internacionais - a nossa rede, da qual falávamos há pouco. Essa mobilização coletiva e articulada é muito importante, porque contribui para a solidariedade coletiva em tempos de crise, além de permitir o compartilhamento de experiências e práticas didáticopedagógicas, que são o campo mais dinâmico de nosso cotidiano.

Maysa Carvalho - Além do Pamin, atualmente, a senhora está envolvida em algum outro projeto? Poderia nos falar sobre?

Luciana Chianca - Sim. Dois projetos me motivam agora: uma pesquisa sobre o patrimônio cultural na região do Brejo Paraibano, e outra de pesquisa e extensão, sobre os saberes e fazeres tradicionais na comunidade quilombola de Mituaçu/PB. O primeiro é com uma equipe de pesquisadores da França, Rio de Janeiro e São Paulo, além da colega Patrícia Ramiro, do DCS/UFPB. O segundo conta com a colega Patrícia Pinheiro do PPGA e com Aina Azevedo, do DCS também da UFPB.

Maysa Carvalho - Quais conselhos a senhora poderia ofertar aos aspirantes a antropólogos e antropólogas?

Luciana Chianca - Observem com cuidado o mundo e as pessoas à sua volta. Ouçam com atenção tudo que estiver ao seu alcance. Leiam sempre que puderem. E reflitam sobre o que ouviram leram, viram e sentiram pelo olfato, tato e na sua sensibilidade. Trabalhem muito e não tenham medo: a gente só aprende caminhando, caindo e se levantando. Amem e divirtam-se muito enquanto viverem. Nunca percam a esperança de viver e de fazer um mundo melhor.

Maysa Carvalho - Professora Luciana, eu agradeço imensamente a oportunidade de entrevistá-la. Gostaria de acrescentar algo para concluir nossa conversa?

Luciana Chianca - Obrigada pelo convite, muito sinceramente. É muito especial participar dessa publicação, principalmente porque essa entrevista contradiz um dito popular que afirma que "santo de casa não faz milagre". E aqui estou eu, em minha casa, confessando os meus! 


\section{Referências}

CHIANCA, Luciana. Patrimônio, memória e tecnologias digitais. In: TOLETINO, A. B. (Org.). Educação patrimonial: educação, memórias e identidades. (Caderno temático 3). João Pessoa: Iphan, 2013, p. 98-105. Disponível em: http://portal.iphan.gov.br/ uploads/publicacao/caderno_tematico_de_educacao_patrimonial_nr_03.pdf. Acesso em: 12/05/20.

CHIANCA, L.; OLIVEIRA, A.; SOUZA, M. C. de. (Orgs.). Vozes do Roger: um cotidiano de festas e de fé. João Pessoa: Editora UFPB, 2019.

CHIANCA, L.; PINHEIRO, P. dos S. (Orgs.). Veredas do patrimônio: políticas contemporâneas e desafios da experiência. João Pessoa: Editora UFPB, 2019.

CHIANCA, L.; TOSCANO, Geovânia. (Orgs.). Nas trilhas da memória: cinema, escola e cotidiano. João Pessoa: Editora UFPB, 2019.

GOLDFARB, Maria P. L.; TOYANSK, M.; CHIANCA, L. O. (Orgs.). Ciganos: olhares e perspectivas. João Pessoa: Editora UFPB, 2019.

Recebido em: 11/05/20.

Aceito em: 12/05/20. 